\title{
The struggle against endometrial cancer: ten years of experience of a tertiary center
}

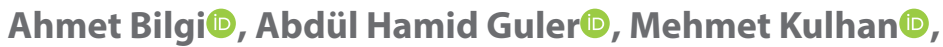

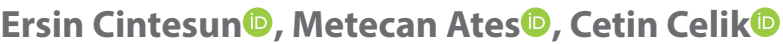 \\ Department of Obstetrics and Gynecology, Selcuk University Medicine Faculty, Selçuklu, Konya, Turkey
}

\begin{abstract}
Objectives: We aimed to investigate the clinical and pathological factors of our patients who were diagnosed with endometrial cancer in terms of prognosis. With this study, we present our 10 years of surgical experience in endometrial carcinoma cases.

Material and methods: Four hundred twelve patients with endometrial carcinoma who applied to our center between 2010-2019 and that we followed up were evaluated retrospectively.

Results: Most of the tumors were low-grade endometrioid malignancies. Non-endometrioid types accounted for $12.1 \%$ of cases. Lymph node dissection was performed in 395 of 412 patients (95.9\%). 66 (16.01\%) of the 412 patients died during the follow-up period in the study sample. Higher OS and DFS rates were associated with endometrioid histological types, FIGO stage, absence of lymphovascular space invasion, lower grade and less than $50 \%$ myometrial invasion $(p<0.05)$. 5-year OS at stage 1, 2, 3, 4 was found as $88.9 \pm 2.2 \%, 65.5 \pm 10.8 \%, 49.4 \pm 0.79 \%$ and $23.7 \pm 0.97 \%$ respectively. 5-year DFS at stage $1,2,3,4$ was found as $84.1 \pm 2.6 \%, 65.5 \pm 10.8 \%, 47.7 \pm 0.78 \%$ and $23.7 \pm 0.97 \%$ respectively. In univariate analysis, Age, tumor histology, FIGO stage, histological grade, LVSI, positive peritoneal cytology, cervical involvement, myometrial invasion and not receiving adjuvant therapy were defined as prognostic factors.

Conclusions: Age, grade, FIGO stage, myometrial invasion, histological type, LVSI involvement, cervical involvemet, positive peritoneal cytology and not receiving adjuvant therapy are important prognostic factors for progression-free survival and overall survival in patients diagnosed with endometrial cancer.
\end{abstract}

Key words: endometrial carcinoma; lymph node; stage; prognostic factors

Ginekologia Polska 2022; 93, 5: 351-360

\section{INTRODUCTION}

Endometrium cancer (EC) is the most common gynecological cancer in developed countries and the second most common gynecological cancer worldwide after cervical cancer [1]. Approximately, 3850 new cases are reported annually and around 520 deaths linked to endometrial cancer are seen in Turkey [2]. Most of the patients are diagnosed at an early stage ( $80 \%$ Stage 1$)$ and the average age at the time of diagnosis is reported to be 63 [3]. The incidence of EC is increasing due to various factors such as increased prevalence of obesity, decreased menopausal hormone therapy with progestins, increased prevalence of diabetes and changes in reproductive behavior (increased prevalence of nulliparity, etc.) [4]. Surgery with hysterectomy and salpingo-oophorectomy is the mainstay of EC treatment. Approach to lymph node evaluation in women with EC is a matter of discussion. The application varies according to different institutions and surgeons. In recent years, a more conservative approach has been adopted, and some criteria have been determined and lymph node dissection has been applied in selected patients. Similarly, sentinel lymph node applications have started to be adopted as a popular approach in endometrial cancers [5]. Routine full bilateral pelvic and paraaortic lymphadenectomy provides the most information about the degree of malignancy for planning adjuvant therapy, but the primary concern for its universal use is lymphedema in the lower extremity and the morbidity of associated cellulitis. In this study, we aimed to present our 10 years of experience in endometrial cancer treatment in our clinic, which is a tertiary center, in terms of surgical, histopathological and prognostic aspects.

\section{Corresponding author:}

Ahmet Bilgi

Department of Obstetrics and Gynecology, Selcuk University Medicine Faculty, Selçuklu, Konya, Turkey

e-mail: abilgi77@gmail.com 


\section{MATERIAL AND METHODS}

This study was approved by the ethics committee decision of our university numbered 2020/508. Four hundred twelve patients who were operated with the diagnosis of EC in our clinic between January 2010 and December 2019 were included in this study. Age, menopausal status, histological type, stage of the disease, histological grade, myometrial invasion, tumor size, lymph node involvement and adjuvant treatments were evaluated retrospectively from the files of the cases. The staging of the cases was done according to FIGO 2009 staging system. We analyzed the clinical characteristics, demographic profiles, pathological data, treatment methods, adjuvant therapies, complications, recurrence, progression-free survival (DFS) and overall survival (OS) of all patients. All cases were pathologically confirmed as EC. DFS was determined from the date of diagnosis to the date of first recurrence or last follow-up, and OS from the date of diagnosis to the date of death or the last follow-up date.

\section{Statistical analysis}

Data are presented as number of observations ( $n, \%)$, mean \pm standard deviation, range. The results of homogeneity (Levene's test) and normality (Shapiro-Wilk test) were used to decide the statistical methods for comparing the study groups. Among normally distributed groups with homogeneous variances, dependent groups were compared using the Student's t-test. According to the test results, parametric test assumptions were not available for some variables; therefore, the independent groups were compared using the Mann Whitney-U test. Categorical data were analyzed using Fischer's exact test and the chi-square test. In cases in which the expected counts for inclusion were not met in less than $20 \%$ of the cells, the "Monte Carlo Simulation Method" was used and the values were determined. Cox regression analysis was used to reveal the model of the relationship between independent variables and dependent variables in the study. In addition, the lifetimes were estimated according to the Kaplan meier estimator. While comparing the survival times of the groups, evaluation was made with the Log Rank test. For the significance level of the tests, $\mathrm{p}<0.05$ and $\mathrm{p}<0.01$ values were accepted.

\section{RESULTS}

During the 10-year study period, 412 histologically confirmed endometrial cancer cases were treated in our institution with primary surgery. The clinicopathological features of the study cohort are shown in Table 1. Most of the tumors were low-grade endometrioid malignancies. High grade tumors consisted of endometrioid grade 3 and non-endometrioid histological types, only non-endometrioid types accounted for $12.1 \%$ of cases. Lymph node dissection was performed in 395 of 412 patients (95.9\%), pelvic + paraaortic lymphadenectomy was performed in 349 cases $(84.7 \%)$, and pelvic lymphadenectomy was performed alone in 46 cases (11.2\%). Lymphadenectomy was not performed in 17 cases (4.1\%). The mean numbers of positive pelvic and paraaortic lymph nodes were 57 (13.8\%) and 34 (8.3\%), respectively.

Postoperative 247 patients (60\%) received adjuvant therapy. Thirty-one patients $(7.5 \%)$ received chemotherapy (CT), 19 patients $(4.6 \%)$ received external radiotherapy (ERT) and 89 patients (21.6\%) received brachytherapy (BRT). Recurrence was detected in 80 patients (19.4\%) during the follow-up period. Recurrence was observed in the pelvic region in 22 (5.34\%) cases, distant metastasis in 16 (3.88\%) case, and pelvic + distant metastasis in 42 (10.2\%) cases.

Sixty-six (16.01\%) of the 412 patients died during the follow-up period in the study sample. OS and DFS for all patients and non-recurrent patients are shown in Figure 1a and $1 \mathrm{~b}$. Higher OS and DFS rates were associated with endometrioid histological types (Fig. 2a, 2b), FIGO stage I (Fig. 3a, 3b), absence of lymphovascular space invasion (LVSI) (Fig. 4a, 4b), lower grade (Fig. 5a, 5b) and less than 50\% myometrial invasion (Fig. 6a, 6b). There was a statistically significant difference between stages in terms of survival $(p<0.05)$. Five-year OS at stage 1, 2, 3, 4 was found as $88.9 \pm 2.2 \%$, $65.5 \pm 10.8 \%, 49.4 \pm 0.79 \%$ and $23.7 \pm 0.97 \%$ respectively. Five-year DFS at stage 1, 2, 3, 4 was found as $84.1 \pm 2.6 \%$, $65.5 \pm 10.8 \%, 47.7 \pm 0.78 \%$ and $23.7 \pm 0.97 \%$ respectively. There is also statistically significant difference between LVSI, grade and histological type, myometrial invasion groups in terms of survival times $(p<0.05)($ Tab. 2).

In univariate analysis, the following parameters were identified as prognostic factors: increased age, histologically non-endometriod type, increased tumor grade, myometrial invasion, advanced FIGO stage, cervical invasion, positivity peritoneal cytology, and not reciewed adjuvant therapy. In the multivariate analysis, advanced age, higher tumor grade, higher FIGO stage, and no adjuvant therapy were found to be associated with lower overall survival (Tab. 3).

\section{DISCUSSION}

Endometrial cancer is divided into two types considering histopathological and molecular markers. Type 1 endometrial cancer is the most common group with a rate of $80-90 \%$ and includes grade 1-2 endometroid type histology. Type 2 endometrial cancer represents the non-endometroid group such as serous, clear cell, undifferentiated carcinomas and carcinosarcomas and is observed at a rate of $10-20 \%$ [6]. Tumor histology of our patients is compatible with the general literatüre. It was determined that 362 (87.9\%) patients had endometrioid type histology, 50 (12.1\%) patients had non-endometrioid type histology. 


\begin{tabular}{|c|c|c|c|c|}
\hline Variable & $\mathrm{n}$ & $\bar{x} \pm S D$ & Median & Range \\
\hline Age & & $59.51 \pm 10.13$ & 59.50 & $33.0-88.0$ \\
\hline Gravida & & $3.51 \pm 2.06$ & 3.0 & $0.0-15.0$ \\
\hline Parity & & $3.30 \pm 1.84$ & 3.0 & $0.0-11.0$ \\
\hline Menopausal status & & $\%$ & & \\
\hline Premenopause $(50<)$ & 70 & 17.0 & & \\
\hline Postmenopause (51 $\leq$ ) & 342 & 83.0 & & \\
\hline \multicolumn{5}{|l|}{ Histological type } \\
\hline Endometrioid & 362 & 87.9 & & \\
\hline Mucinous & 4 & 1.0 & & \\
\hline Serous & 33 & 8.0 & & \\
\hline Clear cell & 2 & 0.5 & & \\
\hline Mixt & 11 & 2.7 & & \\
\hline \multicolumn{5}{|l|}{ FIGO STAGE (2009) } \\
\hline Stage I & 304 & 73.8 & & \\
\hline Stage II & 27 & 6.6 & & \\
\hline Stage III & 56 & 13.6 & & \\
\hline Stage IV & 25 & 6.0 & & \\
\hline \multicolumn{5}{|l|}{ Grade } \\
\hline I & 244 & 59.2 & & \\
\hline ॥ & 95 & 23.1 & & \\
\hline III & 73 & 17.7 & & \\
\hline \multicolumn{5}{|l|}{ Myometrial invasion } \\
\hline$<1 / 2$ & 285 & 69.2 & & \\
\hline$>1 / 2$ & 127 & 30.8 & & \\
\hline \multicolumn{5}{|l|}{ LVSI } \\
\hline$(+)$ & 69 & 16.7 & & \\
\hline$(-)$ & 342 & 83.0 & & \\
\hline \multicolumn{5}{|l|}{ Tumor size } \\
\hline$\leq 2 \mathrm{~cm}$ & 77 & 18.7 & & \\
\hline $2-4 \mathrm{~cm}$ & 166 & 40.3 & & \\
\hline$>4 \mathrm{~cm}$ & 167 & 40.5 & & \\
\hline \multicolumn{5}{|l|}{ Peritoneal cytology } \\
\hline Positive & 34 & 8.3 & & \\
\hline Negative & 378 & 91.7 & & \\
\hline \multicolumn{5}{|l|}{ Lymph node dissection } \\
\hline None & 17 & 4.1 & & \\
\hline Pelvic & 46 & 11.2 & & \\
\hline Pelvic + Paraaortic & 349 & 84.7 & & \\
\hline \multicolumn{5}{|c|}{ Abdominal entry technique } \\
\hline Phannenstiel & 207 & 50.2 & & \\
\hline GAM & 35 & 8.5 & & \\
\hline GAM + GUM & 92 & 22.3 & & \\
\hline Laparoscopic & 78 & 18.9 & & \\
\hline \multicolumn{5}{|l|}{ Adjuvant therapy } \\
\hline Not received & 165 & 40.0 & & \\
\hline
\end{tabular}




\begin{tabular}{|c|c|c|c|c|}
\hline Variable & n & $\overline{\mathbf{x}} \pm S D$ & Median & Range \\
\hline Chemotherapy (CT) & 31 & 7.5 & & \\
\hline External radiotherapy (ERT) & 19 & 4.6 & & \\
\hline Brachytherapy (BRT) & 89 & 21.6 & & \\
\hline$C T+E R T$ & 33 & 8.0 & & \\
\hline $\mathrm{CT}+\mathrm{BRT}$ & 21 & 5.1 & & \\
\hline$C T+R T+B R T$ & 41 & 10.0 & & \\
\hline$E R T+B R T$ & 13 & 3.2 & & \\
\hline \multicolumn{5}{|l|}{ Recurrence } \\
\hline Pelvic & 22 & 5.34 & & \\
\hline Distant & 16 & 3.88 & & \\
\hline Pelvic + distant & 42 & 10.2 & & \\
\hline Death & 66 & 16.01 & & \\
\hline
\end{tabular}

SD — standard deviation; LVSI - lymphovascular space invasion; GAM — sub-umbilical median incision; GUM — median incision above the umbilical; CT — Chemotherapy; ERT — External radiotherapy; BRT — Brachytherapy; RT — radiotherapy

A

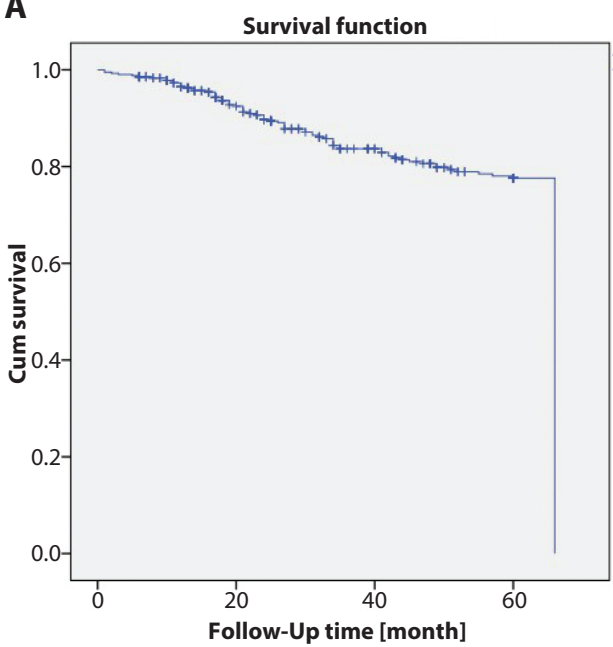

B

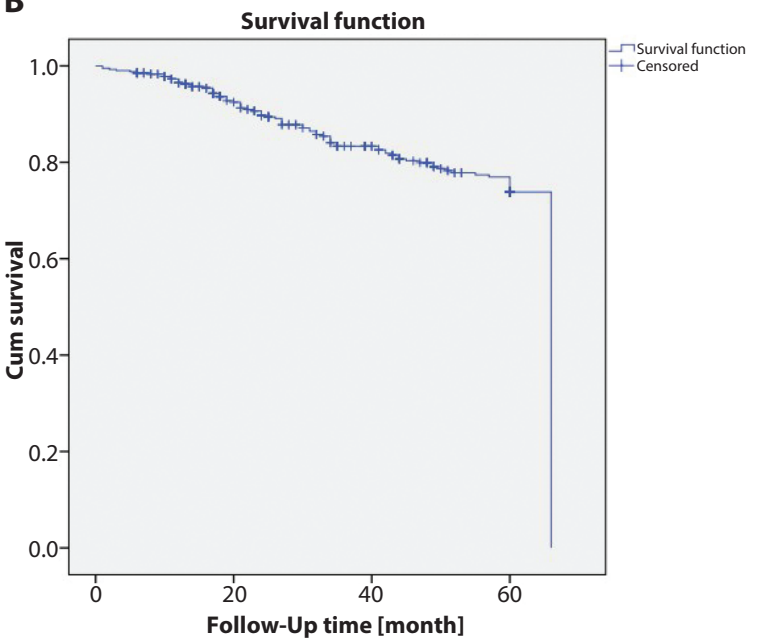

Figure 1A. Overall survival for all patients; B. Disease-free survival for patients without relapse

A

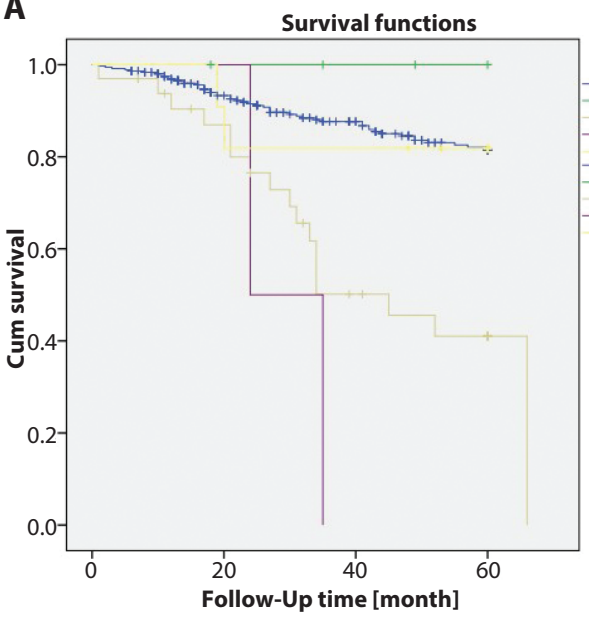

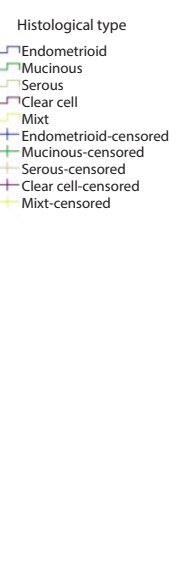

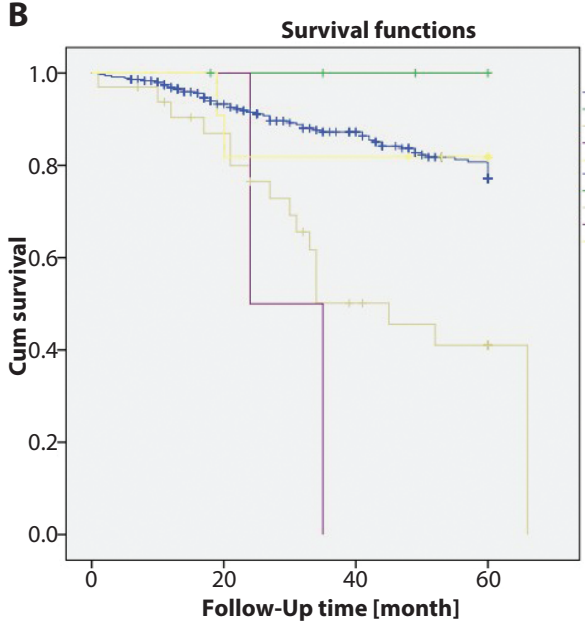

Histological type Endometrioid-censored Serous-censored Clear cell-censored 
A

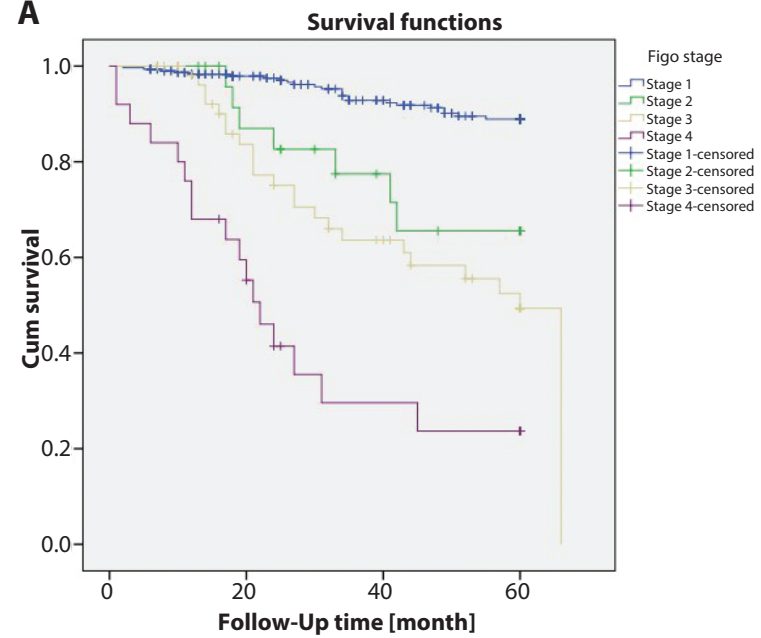

B

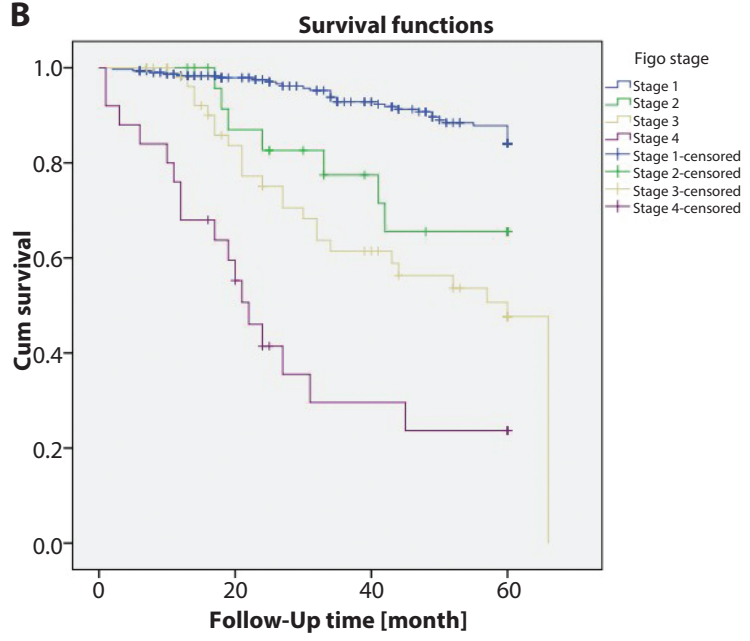

Figure 3A. Overall survival for FIGO stage; B. Disease-free survival for FIGO stage

A

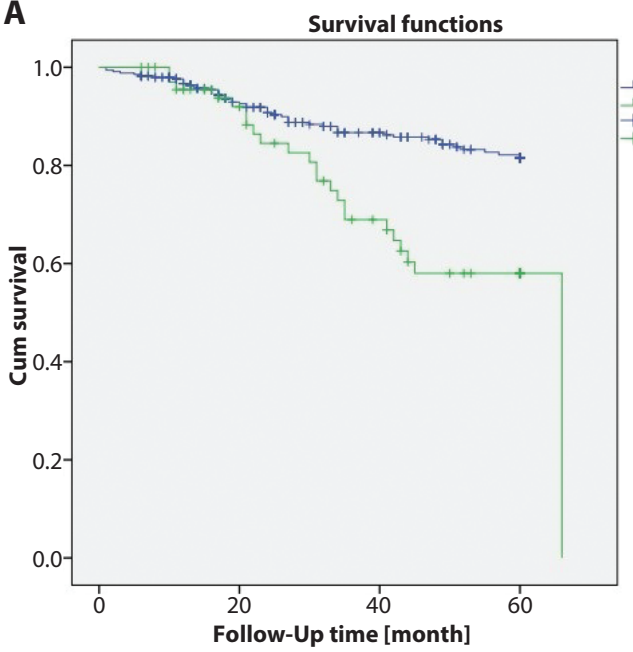

B

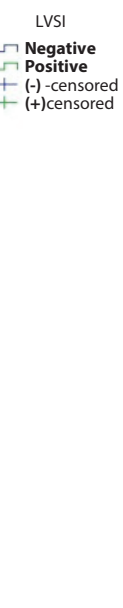

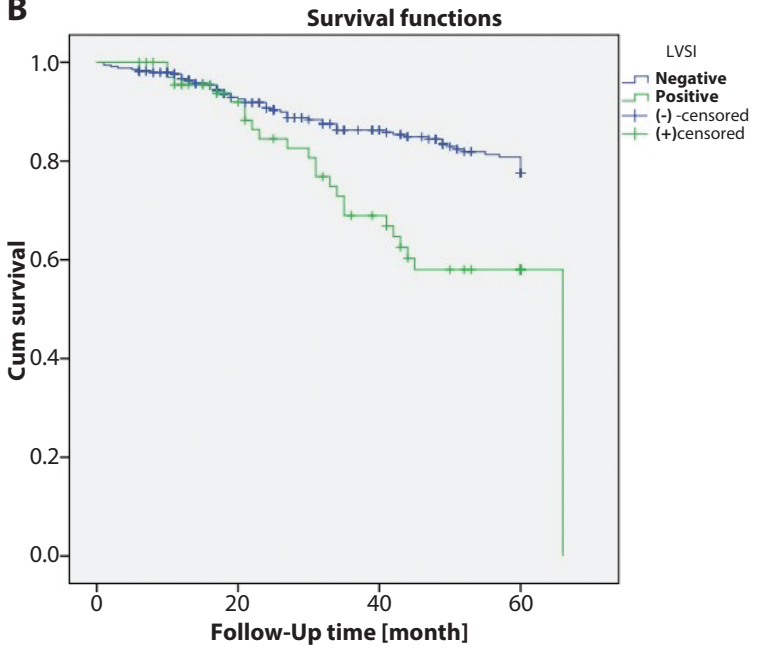

Figure 4A. Overall survival for LVSI involvement; B. Disease-free survival for LVSI involvement

A

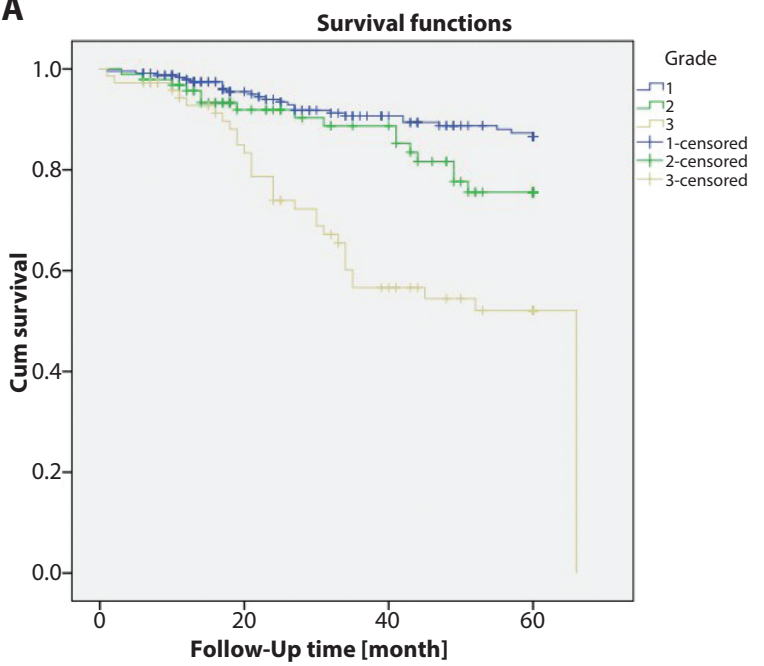

B

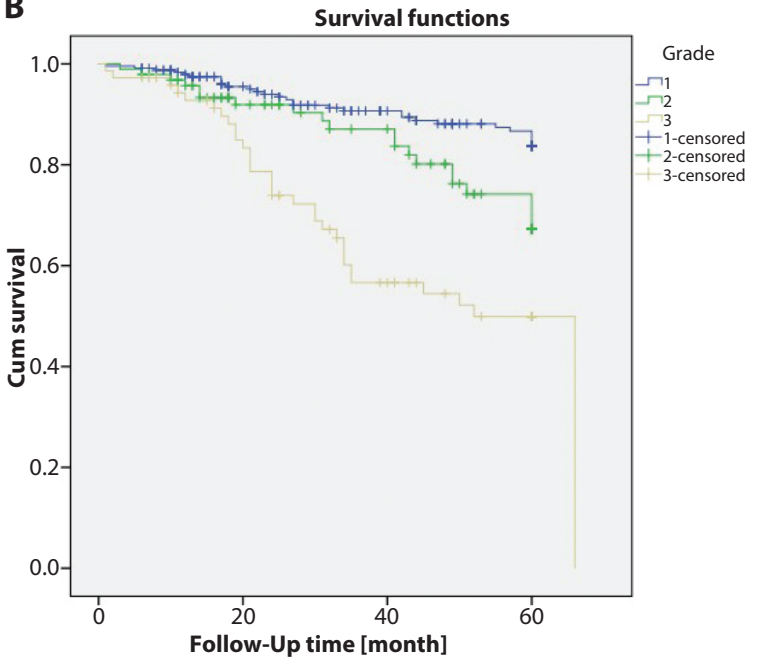

Figure 5A. Overall survival for Grade; B. Disease-free survival for Grade 
A

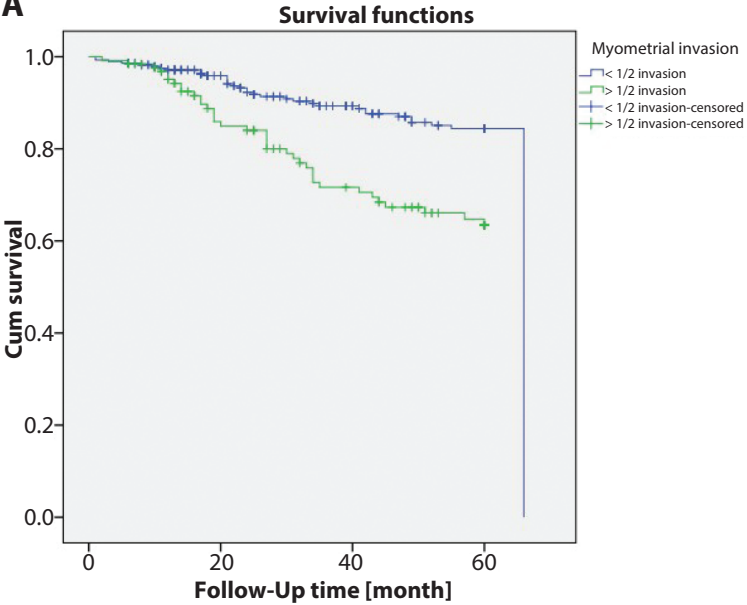

B

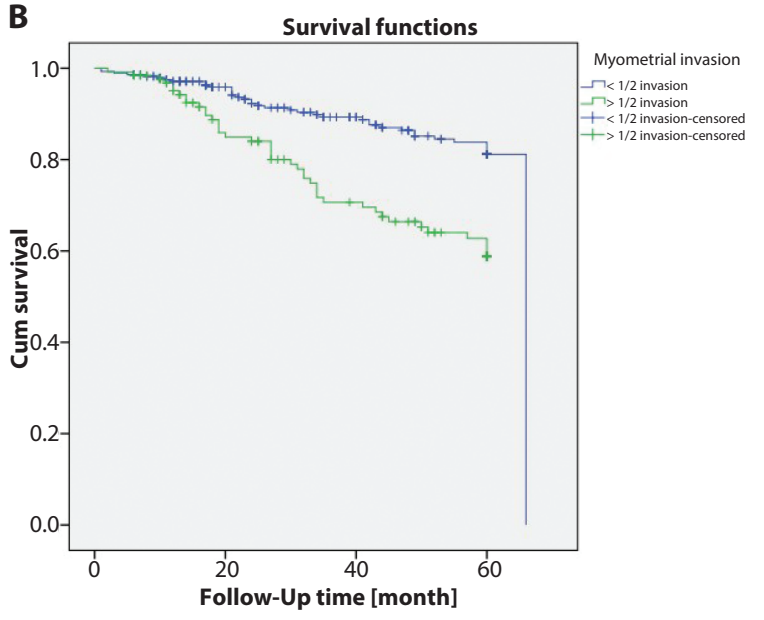

Figure 6A. Overall survival for Myometrial invasion; B. Disease-free survival for Myometrial invasion

\begin{tabular}{|c|c|c|c|c|c|c|c|}
\hline \multirow{2}{*}{ os } & & \multirow{2}{*}{ Estimate } & \multirow{2}{*}{ Std. Error } & \multicolumn{2}{|l|}{$95 \% \mathrm{Cl}$} & \multirow{2}{*}{$x^{2}$} & \multirow{2}{*}{$\mathbf{p}$} \\
\hline & & & & Lower Bound & Upper Bound & & \\
\hline \multirow{3}{*}{ Grade } & 1 & 55.866 & 0.860 & 54.180 & 57.551 & \multirow{3}{*}{37.385} & \multirow{3}{*}{$<0.001$} \\
\hline & 2 & 53.213 & 1.625 & 50.028 & 56.397 & & \\
\hline & 3 & 47.087 & 2.810 & 41.580 & 52.594 & & \\
\hline \multirow{4}{*}{ FIGO Stage } & I & 56.976 & 0.625 & 55.750 & 58.202 & \multirow{4}{*}{125.293} & \multirow{4}{*}{$<0.001$} \\
\hline & ॥ & 49.358 & 3.425 & 42.645 & 56.071 & & \\
\hline & III & 47.736 & 3.167 & 41.528 & 53.943 & & \\
\hline & IV & 28.009 & 4.362 & 19.459 & 36.559 & & \\
\hline \multirow{2}{*}{ LVSI } & Negative & 54.074 & 0.849 & 52.410 & 55.738 & \multirow{2}{*}{13.175} & \multirow{2}{*}{$<0.001$} \\
\hline & Positive & 50.697 & 2.677 & 45.449 & 55.944 & & \\
\hline \multirow{2}{*}{ Myometrial invasion } & $<1 / 2$ & 60.131 & 0.993 & 58.186 & 62.077 & \multirow{2}{*}{17.670} & \multirow{2}{*}{$<0.001$} \\
\hline & $>1 / 2$ & 48.327 & 1.725 & 44.947 & 51.707 & & \\
\hline \multirow{4}{*}{$\begin{array}{l}\text { Abdominal entry } \\
\text { technique }\end{array}$} & Phannenstiel & 55.210 & 1,000 & 53,249 & 57,170 & \multirow{4}{*}{12.659} & \multirow{4}{*}{0.005} \\
\hline & GAM & 50.566 & 2.567 & 45.535 & 55,596 & & \\
\hline & $\mathrm{GAM}+\mathrm{GUM}$ & 53.340 & 2.175 & 49.078 & 57,603 & & \\
\hline & $\mathrm{L} / \mathrm{S}$ & 52.793 & 2.354 & 48.178 & 57.408 & & \\
\hline \multirow{3}{*}{$\begin{array}{l}\text { Lymph node } \\
\text { dissection }\end{array}$} & None & 54.118 & 3.978 & 46.320 & 61.915 & \multirow{3}{*}{0.808} & \multirow{3}{*}{0.668} \\
\hline & Pelvic & 50.534 & 5.116 & 40.507 & 60.561 & & \\
\hline & Pelvic + Paraaortic & 57.435 & 0.995 & 55.485 & 59.386 & & \\
\hline \multirow{3}{*}{ Tumor size } & $<2 \mathrm{~cm}$ & 54.919 & 1.669 & 51.649 & 58.190 & \multirow{3}{*}{3.008} & \multirow{3}{*}{0.222} \\
\hline & $2-4 \mathrm{~cm}$ & 53.178 & 1.251 & 50.725 & 55.630 & & \\
\hline & $>4 \mathrm{~cm}$ & 55.972 & 1.581 & 52.874 & 59.070 & & \\
\hline \multicolumn{8}{|l|}{ DFS } \\
\hline \multirow{3}{*}{ Tumor size } & $<2 \mathrm{~cm}$ & 54.091 & 1.803 & 50.557 & 57.624 & \multirow{3}{*}{1.491} & \\
\hline & $2-4 \mathrm{~cm}$ & 53.178 & 1.274 & 50.682 & 55.674 & & 0.475 \\
\hline & $>4 \mathrm{~cm}$ & 55.745 & 1.577 & 52.654 & 58.837 & & \\
\hline & 1 & 55.764 & 0.861 & 54.077 & 57.452 & & \\
\hline Grade & 2 & 52.795 & 1.700 & 49.463 & 56.128 & 35.566 & $<0.001$ \\
\hline & 3 & 46.202 & 2.789 & 40.735 & 51.669 & & \\
\hline
\end{tabular}




\begin{tabular}{|c|c|c|c|c|c|c|c|}
\hline \multirow{2}{*}{ os } & & \multirow{2}{*}{ Estimate } & \multirow{2}{*}{ Std. Error } & \multicolumn{2}{|l|}{$95 \% \mathrm{Cl}$} & \multirow{2}{*}{$x^{2}$} & \multirow{2}{*}{$\mathbf{p}$} \\
\hline & & & & Lower Bound & Upper Bound & & \\
\hline \multirow{4}{*}{ FIGO Stage } & I & 56.835 & 0.641 & 55.580 & 58.091 & \multirow{4}{*}{111.772} & \multirow{4}{*}{0.001} \\
\hline & ॥ & 49.358 & 3.425 & 42.645 & 56.071 & & \\
\hline & III & 47.059 & 3.157 & 40.871 & 53.247 & & \\
\hline & IV & 28.009 & 4.362 & 19.459 & 36.559 & & \\
\hline \multirow{2}{*}{ LVSI } & Negative & 53.839 & 0.854 & 52.166 & 55.513 & \multirow{2}{*}{9.800} & \multirow{2}{*}{0.002} \\
\hline & Positive & 50.697 & 2.677 & 45.449 & 55.944 & & \\
\hline \multirow{2}{*}{ Myometrial invasion } & $<1 / 2$ & 59.844 & 0.994 & 57.895 & 61.792 & \multirow{2}{*}{18.687} & \multirow{2}{*}{$<0.001$} \\
\hline & $>1 / 2$ & 47.952 & 1.722 & 44.577 & 51.328 & & \\
\hline \multirow{4}{*}{$\begin{array}{l}\text { Abdominal entry } \\
\text { technique }\end{array}$} & Phannenstiel & 54.951 & 1.008 & 52.974 & 56.927 & \multirow{4}{*}{9.333} & \multirow{4}{*}{0.025} \\
\hline & GAM & 50.566 & 2.567 & 45.535 & 55.596 & & \\
\hline & GAM + GUM & 53.177 & 2.164 & 48.935 & 57.418 & & \\
\hline & $L / S$ & 52.114 & 2.393 & 47.425 & 56.804 & & \\
\hline \multirow{3}{*}{$\begin{array}{l}\text { Lymph node } \\
\text { dissection }\end{array}$} & None & 54.118 & 3.978 & 46.320 & 61.915 & \multirow{3}{*}{1.336} & \multirow{3}{*}{0.513} \\
\hline & Pelvic & 50.534 & 5.116 & 40.507 & 60.561 & & \\
\hline & Pelvic + Paraaortik & 56.988 & 0.997 & 55.034 & 58.942 & & \\
\hline
\end{tabular}

$\mathrm{CI}$ - confidence interval; OS - overal survival, DFS - diseases-free survival, LVSI - lymphovascular space invasion, GAM — sub-umbilical median incision, GUM - median incision above the umbilical

Endometrium cancer most often occurs in the 60$-70 \mathrm{~s}$. The average age is 60 . It has been shown that $75 \%$ of the patients are over the age of 50 [7]. Endometrial cancer occurs especially during menopause. Although the prognosis was reported to be better in young patients, there are studies reporting that age is not an independent prognostic factor [8]. In our study, the mean age of our patients was $59.5 \pm 10.13$. Age factor was seen as an independent prognostic factor in univariate and multivariate analyzes. Advanced age was associated with lower overall survival.

Since most of the cases are detected in the early stage, long five-year survival rates are provided with treatment. However, due to the many prognostic factors affecting the biological behavior of the tumor, the optimal surgical treatment is still controversial. Many retrospective studies have shown a statistically significant DFS and OS survival benefit if optimal cytoreduction is achieved $[9,10]$. Seventy-three point eight percent of the patients were in stage I in our study. Pelvic and paraaortic lymph node dissection constitutes an important part of surgical staging in the surgical treatment of endometrial cancer. The role of lymphadenectomy in determining adjuvant treatment as well as staging is obvious. It is important to perform lymph node dissection in sufficient numbers and areas. In this context, Mariani et al. [11], reported that in the case of total pelvic and paraaortic lymphadenectomy, there was no lymph node recurrence in the paraaortic region and lymphadenectomy had therapeutic effect . In a study involving 91 patients diagnosed with stage IIIC, microscopic lymph node involvement was found in 39 patients and macroscopic lymph node involvement in 52 patients [11]. When the 5 -year OS durations were examined, it was found that it was $58 \%$ in cases with microscopic nodal involvement, $41 \%$ in patients with complete resection with macroscopic involvement, and $22 \%$ in patients with incomplete resection [12]. In our study, complete resection was performed in $95.9 \%$ of the cases and the 5 -year OS and DFS values were found as $54.118 \pm 3,978$ month, $54.118 \pm 3.978$ month in those without lymph node dissection, $50.534 \pm 5.116$ month, $50.534 \pm 5.116$ month in those who had only pelvic dissection, $57.435 \pm 0.995$ month, $56.988 \pm 0.997$ months in those who had both pelvic and paraaortic lymph dissection, respectively. Lymphatic metastasis in endometrial cancer is associated with tumor histology, grade, depth of myometrial invasion, and LVSI. Therefore, it seems reasonable to apply systemic lymphadenectomy, especially in early stage disease with these risk factors, except for the advanced stage [12-14].

Surgical staging has a very important place in determining prognosis. Most of the endometrial cancers (80.3\%) are diagnosed at the early stage (FIGO stage I or II) and the 5 -year survival of these varies between $74-91 \%$; this rate is between $57-66 \%$ for stage III disease and $20-26 \%$ for stage IV disease [15]. Endometrial cancer, approximately $16 \%$ at the time of diagnosis, is detected at an advanced stage [16]. According to the surgical-pathological staging, Dane et al. [17], found that The 5-year DFS rate was 
Table 3. Univariate and multivariate analyses for survival in endometrial cancer patients

\begin{tabular}{|c|c|c|c|c|c|c|}
\hline & \multicolumn{3}{|c|}{ UNIVARIATE } & \multicolumn{3}{|c|}{ MULTIVARIATE } \\
\hline & HR & $95 \% \mathrm{Cl}$ & $\mathbf{P}$ & HR & $95 \% \mathrm{Cl}$ & $\mathbf{P}$ \\
\hline Age [years] & 1.082 & $1.057-1.107$ & $<0.001$ & 1.081 & $1.054-1.110$ & $<0.001$ \\
\hline \multicolumn{7}{|l|}{ Hystologic type } \\
\hline Endometrioid & \multicolumn{6}{|l|}{ Reference } \\
\hline Nonendometriod & 2.976 & $1.771-5.001$ & $<0.001$ & 0.520 & $0.232-1.168$ & 0.113 \\
\hline \multicolumn{7}{|l|}{ Tumor grade } \\
\hline 1 & \multicolumn{6}{|l|}{ Reference } \\
\hline 2 & 1.845 & $0.984-3.456$ & 0.056 & 1.398 & $0.712-2.741$ & 0.330 \\
\hline 3 & 4.612 & $2.697-7.886$ & $<0.001$ & 3.569 & $1.572-8.100$ & 0.002 \\
\hline \multicolumn{7}{|l|}{ LVSI } \\
\hline Negative & \multicolumn{6}{|l|}{ Reference } \\
\hline Positive & 2.466 & $1.488-4.088$ & $<0.001$ & 0.752 & $0.381-1.485$ & 0.412 \\
\hline \multicolumn{7}{|l|}{ Tumor diameter } \\
\hline$<2 \mathrm{~cm}$ & \multicolumn{6}{|l|}{ Reference } \\
\hline $2-4 \mathrm{~cm}$ & 1.376 & $0.647-2.927$ & 0.407 & & & \\
\hline$>4 \mathrm{~cm}$ & 1.819 & $0.872-3.793$ & 0.111 & & & \\
\hline \multicolumn{7}{|l|}{ Myometrial invasion } \\
\hline Negative & \multicolumn{6}{|l|}{ Reference } \\
\hline Positive & 2.629 & $1.644-4.203$ & $<0.001$ & 1.005 & $0.578-1.749$ & 0.986 \\
\hline \multicolumn{7}{|l|}{ FIGO Stage } \\
\hline 1 & \multicolumn{6}{|l|}{ Reference } \\
\hline 2 & 3.647 & $1.570-8.468$ & 0.003 & 8.158 & $2.691-24.731$ & $<0.001$ \\
\hline 3 & 5.930 & $3.323-10.584$ & $<0.000$ & 7.027 & $3.146-15.692$ & $<0.001$ \\
\hline 4 & 16.216 & $8.643-30.426$ & $<0.000$ & 23.488 & $8.923-61.824$ & $<0.001$ \\
\hline \multicolumn{7}{|c|}{ Lymph node dissection } \\
\hline None & \multicolumn{6}{|l|}{ Reference } \\
\hline Pelvic & 1.836 & $0.303-11.143$ & 0.509 & & & \\
\hline Pelvic + Paraaortic & 1.884 & $0.461-7.700$ & 0.378 & & & \\
\hline \multicolumn{7}{|l|}{ Cervical invasion } \\
\hline Negative & \multicolumn{6}{|l|}{ Reference } \\
\hline Positive & 2.674 & $1.632-4.381$ & $<0.001$ & 0.642 & $0.311-1.326$ & 0.231 \\
\hline \multicolumn{7}{|l|}{ Peritoneal cytology } \\
\hline Negative & \multicolumn{6}{|l|}{ Reference } \\
\hline Positive & 5.632 & $3.317-9.563$ & $<0.001$ & 1.570 & $0.750-3.288$ & 0.232 \\
\hline \multicolumn{7}{|l|}{ Adjuvan Terapy } \\
\hline No & \multicolumn{6}{|l|}{ Reference } \\
\hline Yes & 1.767 & $1.043-2.993$ & 0.034 & 0.471 & $0.242-0.917$ & 0.027 \\
\hline
\end{tabular}

$\mathrm{Cl}$ - confidence interval

$90 \%$ in stage I, $66 \%$ in stage II, $32 \%$ in stage III and $60 \%$ in stage IV and the 5 -year OS rate was $95 \%$ in stage I, $89 \%$ in stage II. $49 \%$ in stage III, and $30 \%$ in stage IV. These values show that staging is statistically significant as a prognostic factor. In our study, the 5-year OS rate was at stage 1, 2, 3, 4 was found as $88.9 \pm 2.2 \%, 65.5 \pm 10.8 \%, 49.4 \pm 0.79 \%$ and $23.7 \pm 0.97 \%$ respectively. Five-year DFS at stage 1,2 ,
3, 4 was found as $84.1 \pm 2.6 \%, 65.5 \pm 10.8 \%, 47.7 \pm 0.78 \%$ and $23.7 \pm 0.97 \%$ respectively.

Grade is also an important determinant for myometrial invasion and lymph node involvement, which is another prognostic factor. As the differentiation degree of the tumor decreases, the risk of deep myometrial invasion, cervical involvement, lymph node involvement, local recurrence and 
A

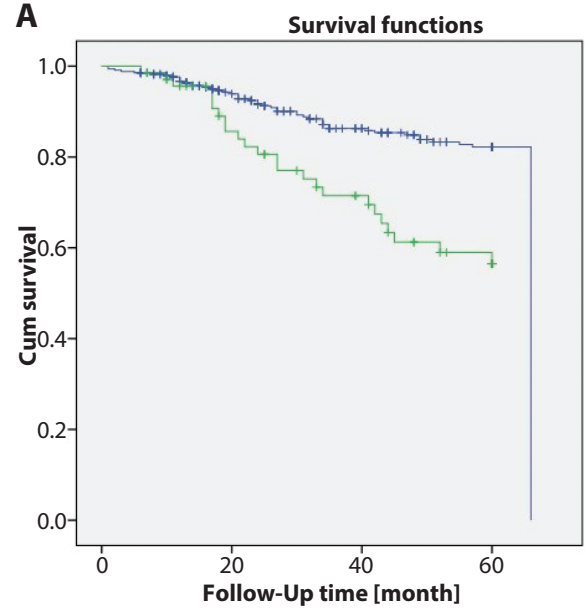

B

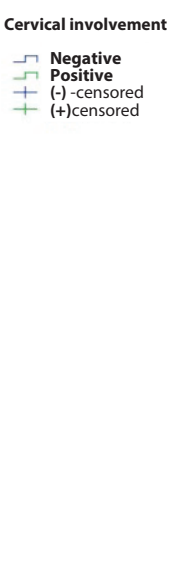

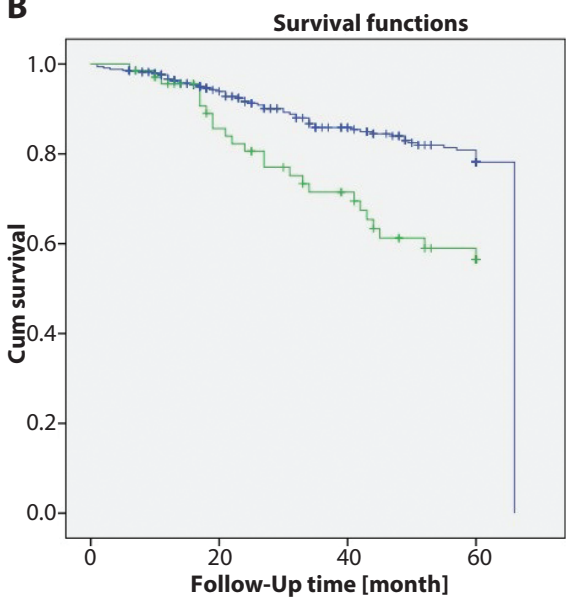

Cervical involvement

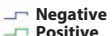

Pogitive
$+(-)$-censore
$+(+)$ censor $+(-)-$ censored
$+(+)$ censored

Figure 7A. Overall survival for Cervical involvement; B. Disease-free survival for Cervical involvement

distant metastasis increases [18]. In the present study, there is a statistically significant difference between the grade groups in terms of OS and DFS $(p<0.01)$. According to the Kaplan-Meier estimator, The OS was 55,866 \pm 0.86 months in the grade $1,53,213 \pm 1,625$ months in the grade 2 and $47,087 \pm 2,810$ months in the grade 3 . The DFS was detected as $55,764 \pm 0,861$ months in grade $1,52,795 \pm 1.7$ month in grade 2 and 46,202 $\pm 2,789$ months in grade 3 .

In the present study, LVSI positivity was detected in 69 (16.7\%) patients. It is reported that LVSI positivity is associated with a high risk of recurrence and poor prognosis [19]. In this study, The OS was found to be $50.697 \pm 2.677$ months in LVSI positive cases and $54.074 \pm 0.849$ months in negative cases. The DFS values are $50.697 \pm 2.677$ and $53.839 \pm 0.854$ months in LVSI positive and negative cases, respectively. Generally, cases with cervical involvement were found to be higher-grade and deeply invasive tumors (Fig. 7a, 7b).

Invasion of the myometrium by tumoral tissues increases the possibility of extrauterine spread and recurrence since drainage into the lymphatic system is easier when the depth is above $50 \%$ [20]. This is the most important pathological finding that determines whether lymphadenectomy will be added to the surgery during the operation. Myometrial invasion is a criterion for the tumor to behave aggressively. In this study, OS and DFS values in cases with less than $50 \%$ myometrial invasion were found to be $60.131 \pm 0.993$ months and $59.844 \pm 0.994$ months, respectively. The same values were $48.327 \pm 1.725$ and $47.952 \pm 1,722$ months for patients with depth of invasion greater than $50 \%$, respectively. Lymph node involvement is the most important prognostic factor in early stage EC [21]. Patients with positive lymph node metastases are six times more likely to develop recurrence [22]. The involvement of the pelvic lymph nodes is a good indicator for the involvement of the paraaortic lymph nodes. However, approximately $11 \%$ of patients with clinical stage I have paraortic lymph node metastasis. In the presence of deep myometrial invasion, pelvic lymph node involvement is $25 \%$ while paraortic involvement is $17 \%$ [23].

This study has some limitations. The first is a retrospective study and limited to the data in the records, so misclassification bias is possible. Also, to obtain a large sample size, patient data were reviewed over 10 years and treatment patterns/practices may have changed during this time.

\section{CONCLUSIONS}

This single-center retrospective analysis confirms that Age, Grade, FIGO stage, myometrial invasion, histological type, positive peritoneal cytology, not receiving adjuvant therapy, LVSI and cervical involvement are important prognostic factors for progression-free survival and overall survival in patients diagnosed with endometrial cancer.

\section{Conflict of interests}

The all author declared that there is no conflicts of interest.

\section{REFERENCES}

1. Lortet-Tieulent J, Ferlay J, Bray F, et al. International patterns and trends in endometrial cancer incidence, 1978-2013. J Natl Cancer Inst. 2018; 110(4): 354-361, doi: 10.1093/jnci/djx214, indexed in Pubmed: 29045681.

2. Gultekin M, Kucukyildiz I, Karaca MZ, et al. Trends of gynecological cancers in Turkey: toward Europe or Asia? Int J Gynecol Cancer. 2017; 27(7): 1525-1533, doi: 10.1097/IGC.0000000000001026, indexed in Pubmed: 28708790.

3. Teter Z, Śliwczyński A, Brzozowska M, et al. The assessment of overall survival (OS) after adjuvant chemotherapy for patients with malignant endometrial cancer in Poland. Ginekol Pol. 2017; 88(6): 296-301, doi: 10.5603/GP.a2017.0056, indexed in Pubmed: 28727127.

4. Cote ML, Ruterbusch JJ, Olson SH, et al. The growing burden of endometrial cancer: A major racial disparity affecting black women. Cancer Epidemiol Biomarkers Prev. 2015; 24(9): 1407-1415, doi: 10.1158/10559965.EPI-15-0316, indexed in Pubmed: 26290568.

5. Sawicki S, Kobierski J, Liro M, et al. Micrometastases in sentinel lymph node in endometrial cancer patients. Ginekol Pol. 2015; 86(4): 262-267, doi: 10.17772/gp/2071, indexed in Pubmed: 26117984. 
6. American College of Obstetricians and Gynecologists. ACOG practice bulletin, clinical management guidelines for obstetrician-gynecologists, number 65, August 2005: management of endometrial cancer. Obstet Gynecol. 2005; 106(2): 413-425, doi: 10.1097/00006250-20050800000050, indexed in Pubmed: 16055605.

7. Creutzberg CL, van Putten WL, Koper PC, et al. Surgery and postoperative radiotherapy versus surgery alone for patients with stage- 1 endometrial carcinoma: multicentre randomised trial. PORTEC Study Group. Post Operative Radiation Therapy in Endometrial Carcinoma. Lancet. 2000; 355(9213): 1404-1411, doi: 10.1016/s0140-6736(00)02139-5, indexed in Pubmed: 10791524.

8. Wu Y, Sun W, Liu X, et al. Age at menopause and risk of developing endometrial cancer: A meta-analysis. Biomed Res Int. 2019; 2019:8584130, doi: 10.1155/2019/8584130, indexed in Pubmed: 31275987.

9. Ayhan A, Taskiran C, Celik C, et al. Surgical stage III endometrial cancer: analysis of treatment outcomes, prognostic factors and failure patterns. Eur J Gynaecol Oncol. 2002; 23(6): 553-556, indexed in Pubmed: 12556104.

10. van Wijk FH, van der Burg MEL, Burger CW, et al. Management of surgical stage III and IV endometrioid endometrial carcinoma: an overview. Int J Gynecol Cancer. 2009; 19(3): 431-446, doi: 10.1111/IGC.0b013e3181a1a04f, indexed in Pubmed: 19407572.

11. Mariani A, Webb MJ, Galli L, et al. Potential therapeutic role of para-aortic lymphadenectomy in node-positive endometrial cancer. Gynecol Oncol. 2000; 76(3): 348-356, doi: 10.1006/gyno.1999.5688, indexed in Pubmed: 10684709.

12. Havrilesky LJ, Cragun JM, Calingaert B, et al. Resection of lymph node metastases influences survival in stage IIIC endometrial cancer. Gynecol Oncol. 2005; 99(3): 689-695, doi: 10.1016/j.ygyno.2005.07.014, indexed in Pubmed: 16126261.

13. Akbayir O, Corbacioglu A, Goksedef BP, et al. The novel criteria for predicting pelvic lymph node metastasis in endometrioid adenocarcinoma of endometrium. Gynecol Oncol. 2012; 125(2): 400-403, doi: 10.1016/j. ygyno.2012.01.051, indexed in Pubmed: 22310644.

14. Zhang C, Wang C, Feng W. Clinicopathological risk factors for pelvic lymph node metastasis in clinical early-stage endometrioid endometrial adenocarcinoma. Int J Gynecol Cancer. 2012; 22(8):
1373-1377, doi: 10.1097/IGC.0b013e318269f68e, indexed in Pubmed: 22932266

15. Quinn M, Benedet J, Odicino $F$, et al. Carcinoma of the uterine cervix FIGO 26th annual report on the results on treatment in gynaecological cancer. Int Gynaecol Obstet. 2006; 95: S43-S103, doi: 10.1016/S00207292(06)60030-1, indexed in Pubmed: 17161167.

16. Ueda SM, Kapp DS, Cheung MK, et al. Trends in demographic and clinical characteristics in women diagnosed with corpus cancer and their potential impact on the increasing number of deaths. Am J Obstet Gynecol. 2008; 198(2): 218.e1-218.e6, doi: 10.1016/j.ajog.2007.08.075, indexed in Pubmed: 18226630.

17. Dane C, Bakir S. The effect of myometrial invasion on prognostic factors and survival analysis in endometrial carcinoma. Afr Health Sci. 2019; 19(4): 3235-3241, doi: 10.4314/ahs.v19i4.47, indexed in Pubmed: 32127901.

18. Kadar N, Malfetano JH, Homesley HD. Determinants of survival of surgically staged patients with endometrial carcinoma histologically confined to the uterus: implications for therapy. Obstet Gynecol. 1992; 80(4): 655-659, indexed in Pubmed: 1407890.

19. Kumar S, Podratz KC, Bakkum-Gamez JN, et al. Prospective assessment of the prevalence of pelvic, paraaortic and high paraaortic lymph node metastasis in endometrial cancer. Gynecol Oncol. 2014; 132(1): 38-43, doi: 10.1016/j.ygyno.2013.10.002, indexed in Pubmed: 24120926.

20. Kaku T, Tsuruchi N, Tsukamoto $\mathrm{N}$, et al. Reassessment of myometrial invasion in endometrial carcinoma. Obstet Gynecol. 1994; 84(6): 979-982, indexed in Pubmed: 7970481.

21. Kitchener H, Swart AMC, Qian Q, et al. ASTEC study group. Efficacy of systematic pelvic lymphadenectomy in endometrial cancer (MRC ASTEC trial): a randomised study. Lancet. 2009; 373(9658): 125-136, doi: 10.1016/S0140-6736(08)61766-3, indexed in Pubmed: 19070889.

22. Mariani A, Webb MJ, Rao SK, et al. Significance of pathologic patterns of pelvic lymph node metastases in endometrial cancer. Gynecol Oncol. 2001; 80(2): 113-120, doi: 10.1006/gyno.2000.6050, indexed in Pubmed: 11161847.

23. Panici PB, Basile S, Maneschi F, et al. Systematic pelvic lymphadenectomy vs no lymphadenectomy in early-stage endometrial carcinoma: randomized clinical trial. JNCI Journal of the National Cancer Institute. 2008; 100(23): 1707-1716, doi: 10.1093/jnci/djn397. 